\title{
Contribuições de Sessões Colaborativas na Geração de Ideias em Ambiente Institucional Mediadas pelo Design: experiências em uma instituição de ensino
}

Contributions of Collaborative Sessions in the Generation of Ideas in Institutional Environment Mediated by Design: experiences in a teaching institution

PINA, Suzana Angélica da Silva Mascarenhas; Mestre; UFBA

pina.suzana@gmail.com.br

MAGALHÃES, Ana Luiza Medeiros Guimarães; Especialista; SENAI CIMATEC

analuizaguimaraes@gmail.com

SANTOS, Neymar Leonardo dos; Especialista;

neymarleonardo@gmail.com

SOUZA, Paulo Fernando de Almeida; Doutor; UFBA

paulodesign@gmail.com

\section{Resumo}

É percebido que o design está alcançando destaque em todos os meios de produção criativa, principalmente como elemento importante no desenvolvimento estratégico dos negócios. Deste modo, a pesquisa tem o objetivo de apresentar contribuições de sessões colaborativas na geração de ideias mediadas pelo design em ambientes institucionais, fundamentada nas experiências realizadas em uma instituição de ensino, com coordenadores de curso, a fim de, posteriormente, compartilhar aprendizados com os alunos e potencializar os resultados dos projetos de final de curso. A partir de uma pesquisa qualitativa e exploratória, partiu-se do potencial do Design em explorar os eixos investigativos da percepção e valor, envolvendo pessoas; do valor e função, abrangendo mercado; da função e forma, compreendendo tecnologia; e da percepção e forma, compreendendo a arte em um contexto pré-estabelecido. Com base nesses conceitos, explorou-se a percepção, reflexão, produção e crítica no processo criativo, elevando o número de soluções dos problemas trabalhados.

Palavras Chave: Design e criatividade; sessões colaborativas; educação em design.

\section{Abstract}

It is perceived that design is reaching prominence in all means of creative production, mainly as an important element in the strategic development of the business. In this way, the research has the objective of presenting contributions of collaborative sessions in the generation of ideas mediated by the design in institutional environments, based on the experiences realized in an educational institution, with course coordinators, in order to later share learning with the students and boost the results of the end-of-course projects. From a qualitative and exploratory research, it was based on the potential of the Design in exploring the investigative axes of perception and value, involving people; of value and function, covering market; of function and form, comprising technology; and perception and form, understanding art in a pre-established context. Based on these concepts, the 
perception, reflection, production and critique in the creative process was explored, increasing the number of solutions of the problems worked

Keywords: Design and creativity; collaborative sessions; education in design.

\section{Introdução}

O presente estudo parte do pressuposto de que os projetos desenvolvidos no período da formação acadêmica, e até posteriormente a ela, podem obter resultados mais relevantes com processos mediados pelo design, utilizando-se de recursos metodológicos e ferramentas de criatividade, de modo a alcançar soluções mais aderentes aos requisitos apresentados no escopo dos projetos. Diante dessa situação, foram realizadas sessões colaborativas (BROWN, 2010; SAMPAIO, 2016; MANZINI, 2008; GUERRERO, 2001) com coordenadores e orientadores de projetos finais de curso de uma instituição de ensino, visando promover experiências que apurem as percepções inexploradas, visando compartilhar, posteriormente, com os alunos em fase final de formação.

Segundo Terra et. al (2012, p.77), “o maior desperdício nas empresas está relacionado à subutilização da capacidade criativa das pessoas", com isso, propõe-se uma imersão em sessões colaborativas que favoreçam o processo criativo, promovendo experiências que permitam às equipes de projetos, selecionar os processos adequados para atender aos objetivos do mesmo; usar uma abordagem definida para adaptar planos e especificações do produto; atender aos requisitos para satisfazer necessidades, expectativas e desejos das partes interessadas; e balancear as demandas conflitantes para produzir um produto de qualidade.

O Design apresenta-se neste processo como um mediador de conhecimentos que são integrados internamente aos processos de criação de valor em produtos, conseguindo abranger os conhecimentos destacados nos quadrantes esquematizados na figura 01 , o qual explora os eixos investigativos da percepção e valor, envolvendo pessoas; do valor e função abrangendo o mercado; da função e forma compreendendo a tecnologia; e da percepção e forma, compreendendo a arte.

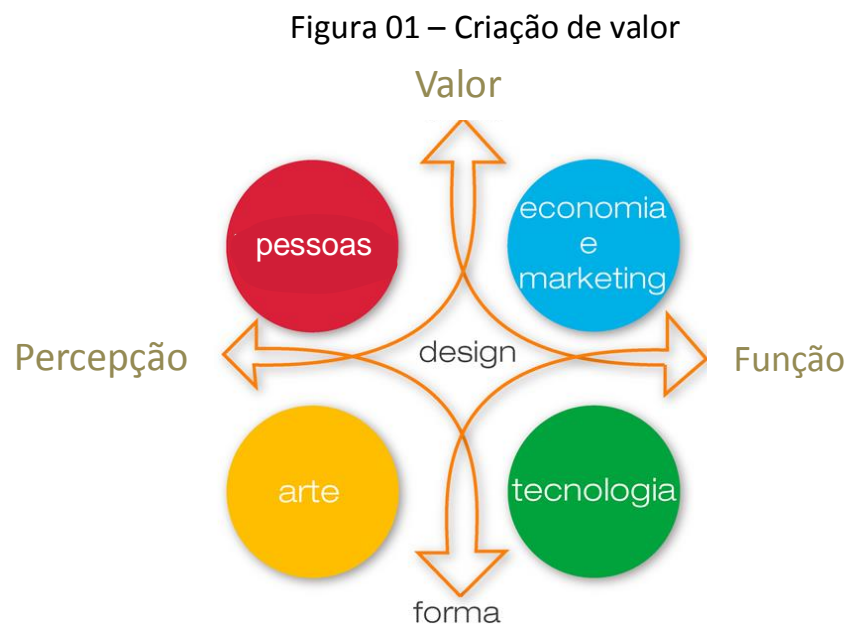

Fonte: Deserti (2012) 
Após as experiências das sessões colaborativas, os resultados da pesquisa poderão contribuir para a academia, agregando nova abordagem às ações já existentes no desenvolvimento de projetos finais de curso, podendo tornar-se um diferencial competitivo, gerando novos conhecimentos para as atividades de Pesquisa e Desenvolvimento (P\&D) relacionados às áreas afins.

Para alcançar o escopo da pesquisa, propõem-se os seguintes objetivos específicos:

a) Promover sessões colaborativas com coordenadores de cursos;

b) Aplicar ferramentas de criatividade utilizando o método colaborativo;

c) Aplicar a metodologia colaborativa nas oficinas de criatividade;

d) Expor os resultados do processo criativo;

e) Proporcionar trocas de conhecimentos entre equipes multidisciplinares;

f) Promover o estímulo para a disseminação das experiências na formação acadêmica.

O método colaborativo surge como uma ferramenta para promover a cultura de cooperação, tendo em vista confirmar, com base no pensamento de De Masi (2003), que a criatividade humana consegue atribuir uma forma ao caos, um significado às coisas, e a definição de um processo metodológico mediado pelo design, pode contribuir com o desenvolvimento do pensamento criativo, visando alcançar resultados satisfatórios no desenvolvimento de projetos. De Masi (2003) reforça em sua obra que a maior parte das criações humanas não são oriundas do ser individual, mas da coletividade, nas quais colaboram para o alcance de uma meta compartilhada. Na atualidade, as grandes descobertas não decorrem de um único autor, mas do aporte de equipes focadas na busca de soluções para os problemas coletivos (DE MASI, 2003).

Diante do objeto de estudo, Silva Filho (2013) afirma que o processo criativo requer três habilidades humanas: a análise, o mapeamento e a síntese e ainda expõe que sendo o momento criativo dinâmico e fruto de compilação de ideias e combinação desses três fatores, a análise gera a habilidade de pensar de modo crítico, com raciocínio convergente, enquanto que o mapeamento, transforma algo abstrato em algo real e prático, com a capacidade de comunicar e vender ideias. Já a síntese traz uma linha de raciocínio divergente, por meio de uma capacidade imaginativa, "com a habilidade de conceber novas ideias ou produtos resultantes de um conjunto de ideias já existentes, sejam elas relacionadas ou não" (SILVA FILHO, 2013, p. 46).

Silva Filho (2011, p. 10) ainda considera que "os fatores determinantes de decisões fazem uso dos três pilares ou D's (dados, determinação e desejo) da tomada de decisão" e solução de problemas que atuam em conjunto com a criatividade nesse processo, criando uma relação com as práticas que foram desenvolvidas nas sessões colaborativas realizadas com os coordenadores.

Com base nesses conceitos, é possível fazer uma relação com o desenvolvimento da percepção, reflexão, produção e crítica na geração de ideias e processos criativos mediados pelo design com práticas experimentais. Reforçando as contribuições neste processo, as oficinas criativas promoveram momentos de dinâmica para melhor observar a situação problema, utilizando ferramentas de auxílio ao processo de construção das soluções, também fundamentadas nas metodologias do Design Thinking (BROWN, 2010; VIANNA, 2013).

Nas sessões colaborativas foram realizadas oficinas com a aplicação de ferramentas de criatividade, com práticas que visam desbloquear o pensamento criativo dos participantes. Para isso, foram selecionados produtos de mercado e formadas equipes multidisciplinares compostas 
por coordenadores de curso de competências distintas para participação nas experiências, de modo a promover olhares mais abrangentes no desenvolvimento das soluções.

As oficinas foram mediadas por três designers, sendo apresentadas as ferramentas que seriam utilizadas em cada sessão. As etapas da experiência foram detalhadas pelos orientadores das equipes e os resultados foram catalogados e analisados. Posteriormente, foram finalizados com os registros dos resultados alcançados e fotos das vivências.

A proposta da pesquisa visa orientar as equipes responsáveis pelos projetos finais de curso, no desenvolvimento de suas habilidades criativas, preparando-os para resolver problemas, pensar de forma criativa, tomar decisões, trabalhar em equipe, gerenciar recursos, inovar e lidar com seus anseios durante o processo.

\section{Metodologia}

Todo processo de desenvolvimento das sessões foi baseado na construção de cenários, utilizando recursos humanos e materiais, além de promover a aplicação de ferramentas de criatividade para solução dos desafios. As oficinas tiveram mediadores que contribuíram com a organização das ideias e experiências, realizando registros fotográficos e aplicação de questionários de avaliação das sessões. Todo material desenvolvido foi recolhido e avaliado posteriormente às oficinas.

Para melhor entendimento do processo, as sessões foram divididas em quatro (04) práticas, onde foram detalhados o objetivo, método (instrumentos e meios aplicados), tempo, materiais utilizados para realizar as atividades. Neste processo foi utilizada a ferramenta de desconstrução do produto e elaboração do painel de referência - moodboard (MCDONAGH e DENTON, 2005), o qual apresenta um maior apelo visual, que utiliza colagem de ideias e inspirações para diversos tipos de trabalhos, como por exemplo, referências de valor desejadas ao produto após a finalização do projeto. Os quais apresentam resultados que não são apenas representações visuais, são um conjunto de informações que representam a emoção que se deseja retratar em toda a obra porque é a emoção que cria a aparência de um projeto. Os moodboards são definidos como: "meios de comunicação visual ou multissensorial (textura, movimento, som) que podem ser úteis na construção do processo de comunicação e design". (MCDONAGH e DENTON, 2005, p.36).

Outro recurso, como o método 635 ou brainwriting 635 (PAZMINO, 2015), é uma ferramenta criativa baseada no Brainstorming e busca soluções para problemas de projeto, com uma equipe multidisciplinar, por meio de um formulário, permitindo obter o maior número de ideias e sugestões de soluções em curtíssimo período de tempo.

A última técnica desta oficina é denominada de MESCRAI, que se trata de "[...] uma sigla de 'Modifique (aumente, diminua.), Elimine, Substitua, Combine, Rearranje, Adapte, Inverta" os quais "[...] funcionam como uma lista de verificação para estimular possíveis modificações no produto". (BAXTER, 2008, p. 80).

\section{Desenvolvimento das Sessões Colaborativas}

No primeiro momento das sessões foram apresentadas as ferramentas de criatividade e desenvolvimento de produtos para estimular o processo criativo nos participantes da oficina, visando um melhor desempenho em suas funções e no estímulo dos seus alunos nas disciplinas e competições que tenham como objetivo a geração de produtos e ideias inovadoras. 
Como método, foram geradas novas alternativas a partir da ressignificação de um produto apresentado para a análise e desenvolvimento das ações, utilizando ferramentas de criatividade: DESCONSTRUÇÃO DE PRODUTOS, PAINEL DE REFERÊNCIA OU MOODBOARD, MÉTODO 635 e MESCRAI.

Foi determinado um período de oito horas para realização da sessão colaborativa, em julho de 2016, composta por três grupos formados por cinco coordenadores, utilizando os seguintes materiais para execução das atividades: canetas, lápis, borracha, papel A4 e A3 (resma), cola, tesoura, revistas diversas, catálogos de produtos, murais de imagens, canetas coloridas, post it, fichas impressas, fita adesiva e Flip-Chart.

Descrevendo a atividade, temos a construção do painel de referência ou moodboard, o qual refere-se a um mural de indicações visuais para representar o conceito visual do projeto. É uma construção formada por composições de Imagens: desenhos, formas, texturas, textos, objetos, cores, padronagens, estáticas de campanha, identidades visuais de produtos semelhantes, entre outros. Com isso, foram apresentados os passos para realização da atividade:

- 10 passo: observar a imagem do produto (Figura 02) que foi apresentada como exemplo para desenvolvimento da atividade, buscando identificar os detalhes construtivos e percepções visuais dos participantes, instigando um novo olhar para construção do painel de desconstrução.

\section{Figura 02 - Produto referência - exemplo}

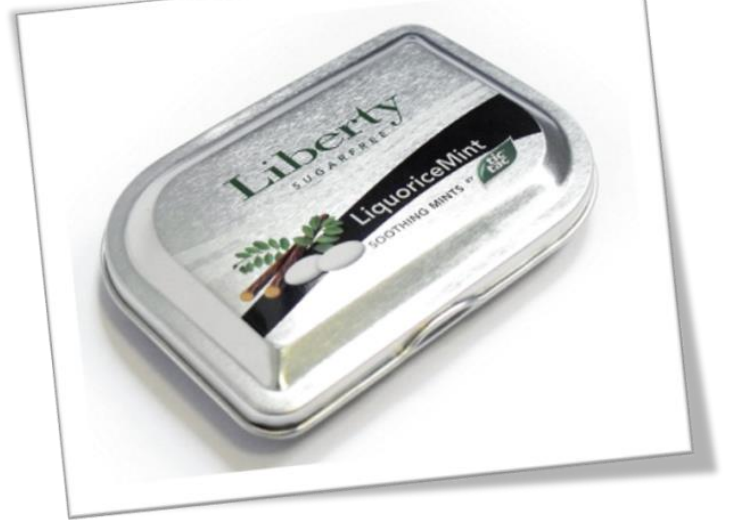

Fonte: Caravegna (2011)

- 20 passo: perceber o processo de construção do produto e sua relação com as referências, tais como imagens, fontes, identidade, cor, textura, formas, dentre outras, as quais foram extraídas para compor o objeto final, a fim de elaborar um painel de desconstrução conforme exemplo da figura 03, que apresenta os recortes da embalagem, produto de referência, destacando os detalhes identificados. 
Figura 03 - Produto referência - exemplo painel de desconstrução
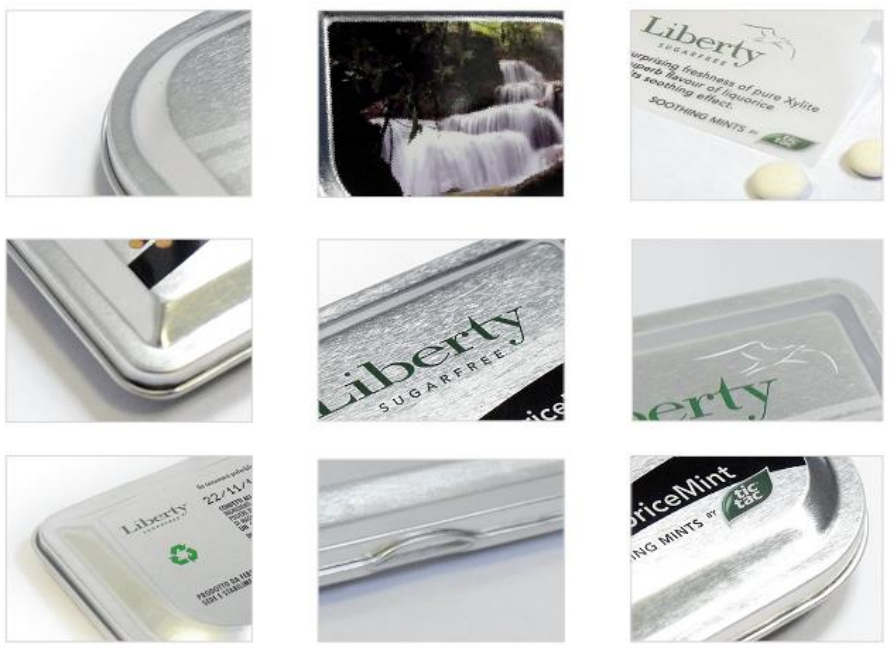

Fonte: Caravegna (2011)

- 3o passo: Elaborar o painel de referência (Figura 04) com base nos elementos, para construção do conceito, fazendo uma relação com os signos identificados que remetem ao produto de origem, conforme apontado abaixo:

Figura 04 - Produto referência - exemplo painel de referências

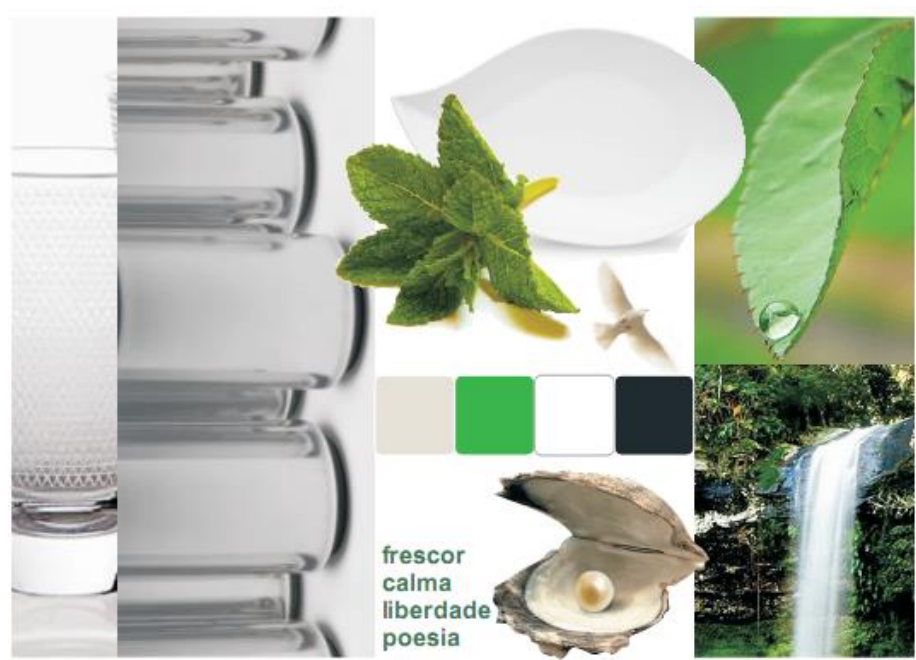

Fonte: Caravegna (2011)

Com base no exemplo, as equipes foram orientadas a iniciar a montagem do painel com a desconstrução e o painel de referência do produto que o grupo recebeu (Figura 05). Ao realizar a desconstrução, foram feitas anotações sobre as características mais relevantes do produto: formas, materiais, superfícies, cores, estilos, texturas e aspectos tangíveis e intangíveis. 
Figura 05 - Produtos propostos para oficina - ferro de passar e cafeteira
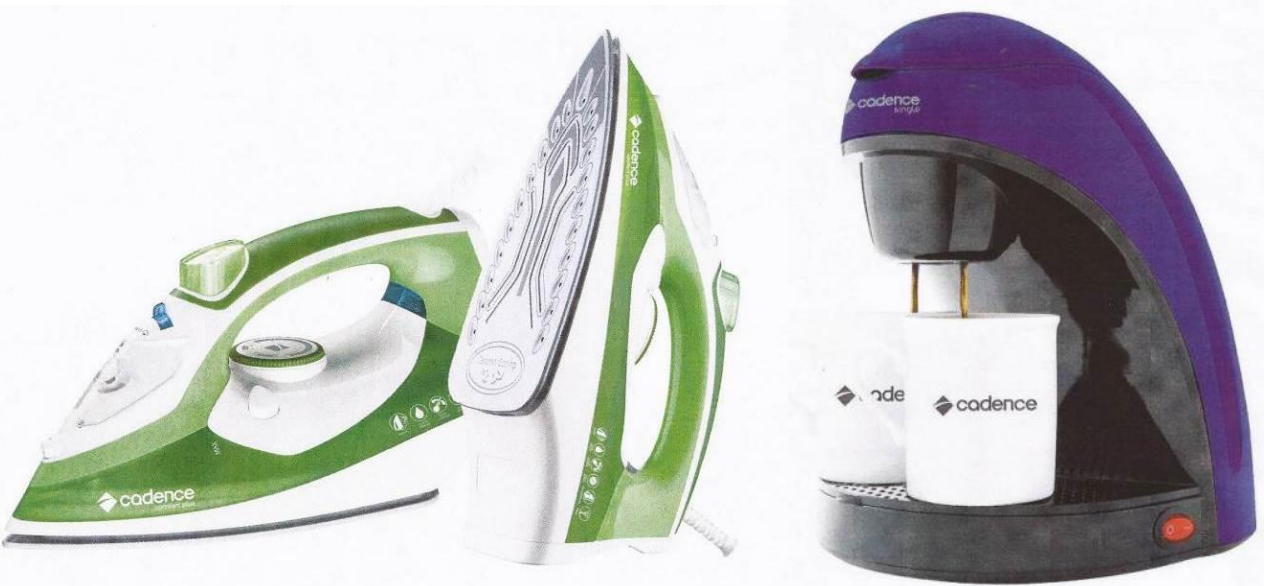

Fonte: http://www.cadence.com.br

- 4ㅇ passo: com base no exemplo, foi conduzida a aplicação da segunda ferramenta, o MÉTODO 635 ou BRAINWRITING 635 (PAZMINO, 2015, p. 215). Tal ferramenta é conduzida pelo líder no processo, no qual lança o desafio, para que as novas ideias comecem a surgir em torno da solução do problema. Cada um dos membros recebe uma folha dividida em 18 espaços de $6 \times 3$ (Figura 06).

Figura 06 - Produtos propostos para oficina

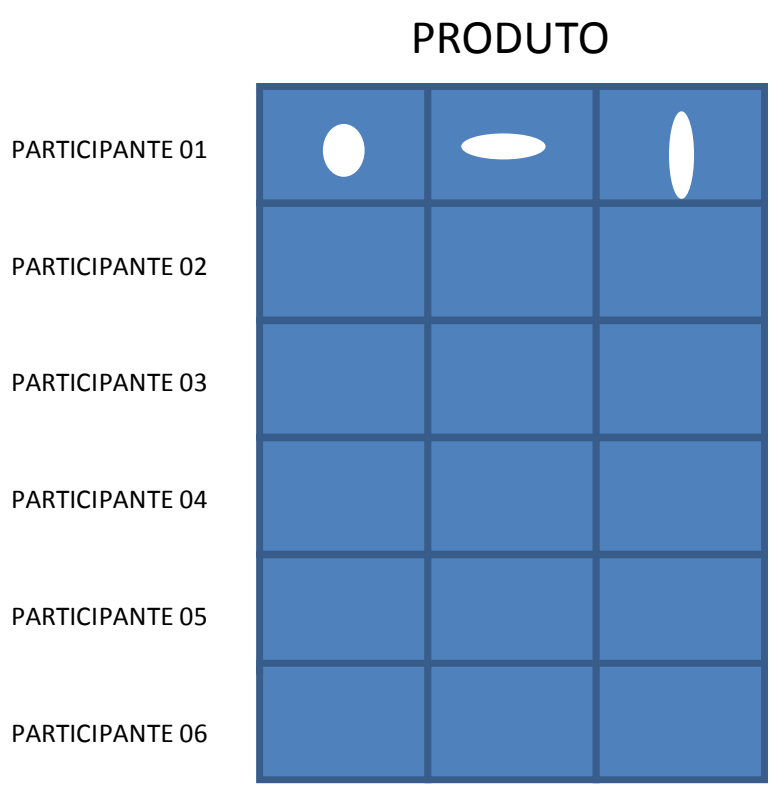

Fonte: adaptado de Pazmino (2015, p. 215).

Cada componente propõe na folha 3 (três) sugestões de solução por um tempo de 5 min. Em seguida passa a folha e recebe a folha do outro participante. Cada um deve dar continuidade à ideia do parceiro na segunda linha, com sugestões novas da ideia anterior ou de melhorias à ideia 
original. O processo é contínuo, até que todos tenham contribuído com a ideia dos parceiros. É uma atividade que deve ser desenvolvida em silêncio para promover maior produtividade e eficácia na elaboração das propostas.

Por meio do uso dessa ferramenta pode-se analisar cada elemento que compõe o projeto por diferentes pontos de vista. No uso desse procedimento surgem novas ideias sobre sua composição ou mesmo sobre sua aplicação, uso, significados e desdobramentos.

- 50 passo: tendo como referência a análise e seleção da alternativa que mais atende aos requisitos propostos para geração do conceito, aplicou-se a ferramenta MESCRAI (Figura 07), de modo a chegar à melhor alternativa de conceito do produto.

Figura 07 - MESCRAI

\begin{tabular}{|l|l|}
\hline $\begin{array}{l}\text { MODIFIQUE } \\
\text { Dimplie/ }\end{array}$ & $\begin{array}{l}\text { O que posso aumentar, diminuir? } 0 \text { que posso deixar mais } \\
\text { resistente, que componentes posso diminuir? }\end{array}$ \\
\hline ELIMINE & 0 que posso eliminar? Do que posso me desfazer? \\
\hline SUBSTITUA & $\begin{array}{l}\text { 0 que posso substituir no material, no processo, na forma, na } \\
\text { interface, na aparência, etc.? }\end{array}$ \\
\hline COMBINE & $\begin{array}{l}\text { 0 que posso combinar no material, nas cores, nos processos? Que } \\
\text { funções posso combinar? }\end{array}$ \\
\hline REARRANJE & $\begin{array}{l}\text { Como posso mudar a ordem, a sequência, etc.? 0 que posso } \\
\text { reestruturar? } 0 \text { que posso inverter? }\end{array}$ \\
\hline ADAPTE & $\begin{array}{l}\text { 0 que posso copiar? o que pode ser adaptado? Que analogias } \\
\text { posso aplicar? }\end{array}$ \\
\hline
\end{tabular}

Fonte: BAXTER, 2008, p. 80.

\subsection{Resultados}

As oficinas realizadas promoveram as seguintes etapas e experiências:
a) Apresentar o problema ou desafio
b) Ampliar o repertório de soluções de problemas
c) Estimular o processo de soluções colaborativas
d) Auxiliar na geração de ideias
e) Definir o conceito do produto
f) Comunicar visualmente 
g) Definir a estética

h) Apresentar as tendências e macrotendências

i) Formar conceitos

j) Transmitir sentimentos

k) Provocar reações

l) Contribuir no processo criativo

m) Contribuir para o uso de ferramentas de criatividade no processo de ideação.

A seguir são apresentados os registros das sessões colaborativas, por meio de fotos do ambiente e algumas evidências do processo criativo e da vivencia dos grupos durante a troca de saberes proporcionada pelas atividades descritas anteriormente.

Nas figuras $08,09,10$, e 11, cada equipe elaborou o moodboard com os recortes das partes do produto selecionado (cafeteira ou ferro de passar). Fase de descontruir e montar as referências formais e funcionais.

Figura 08, 09, 10 e 11 - Construção do Moodboard

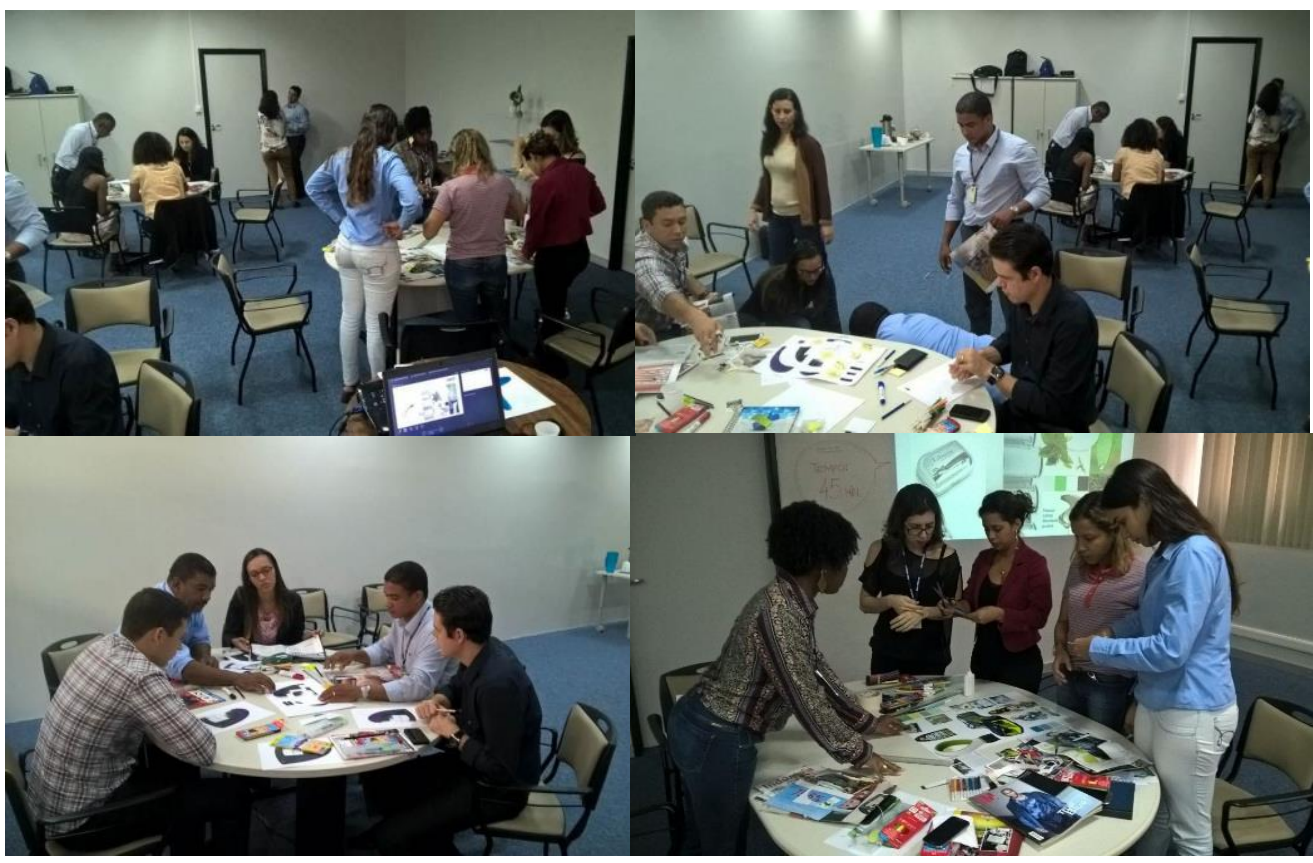

Fonte: Próprios autores.

Com os produtos de estudo em mãos, entregues pelos mediadores, os participantes dos grupos selecionaram as partes e fizeram o painel de desconstrução, conforme visto nas figuras $12 \mathrm{e}$ 13, o que permite ter um detalhamento de partes do produto, consentindo retirar referências para a construção do segundo painel, moodboard. 


\section{Artigo Completo}

Figura 12 e 13 - Moodboard - desconstrução do produto

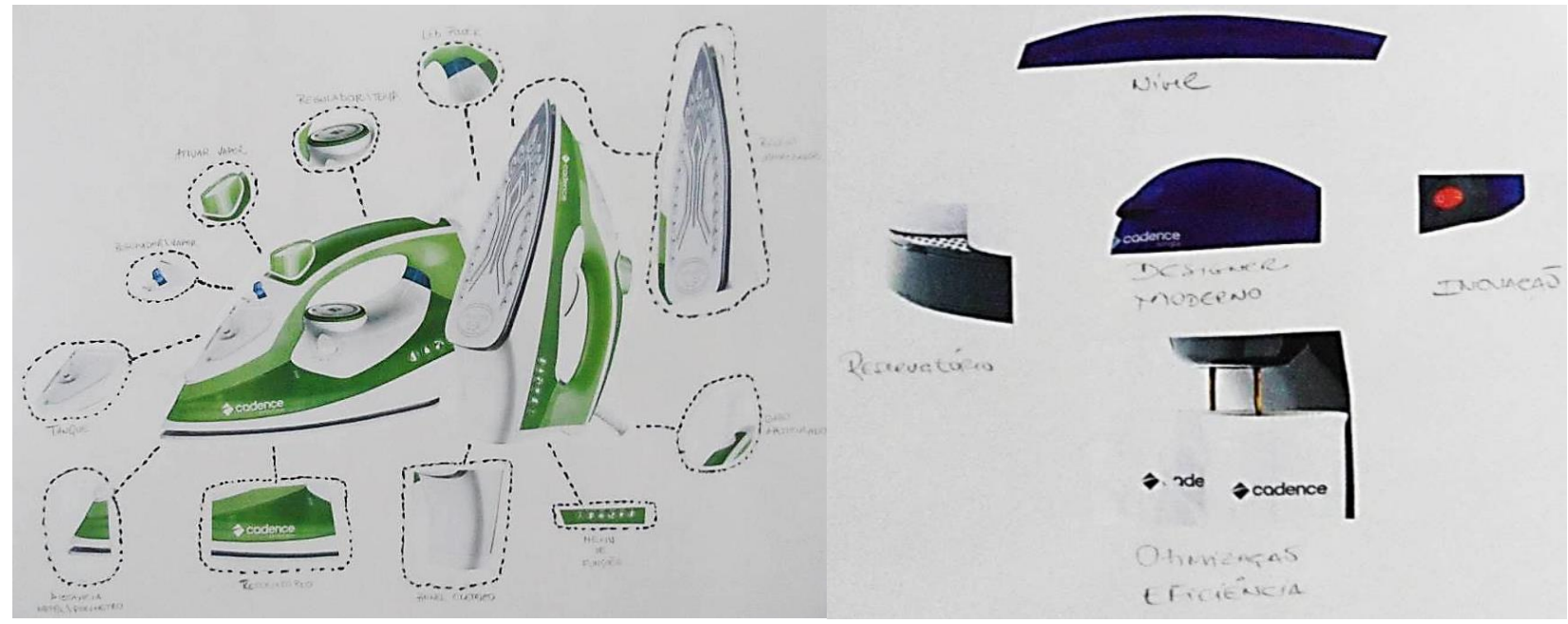

Fonte: Elaborado pelos autores com base na pesquisa realizada.

Com base nos elementos do painel de desconstrução, foram elaborados os painéis moodboard de referência (Figura 13), para posterior apresentação dos resultados.

Figura 13 - Construção do Moodboard de referência

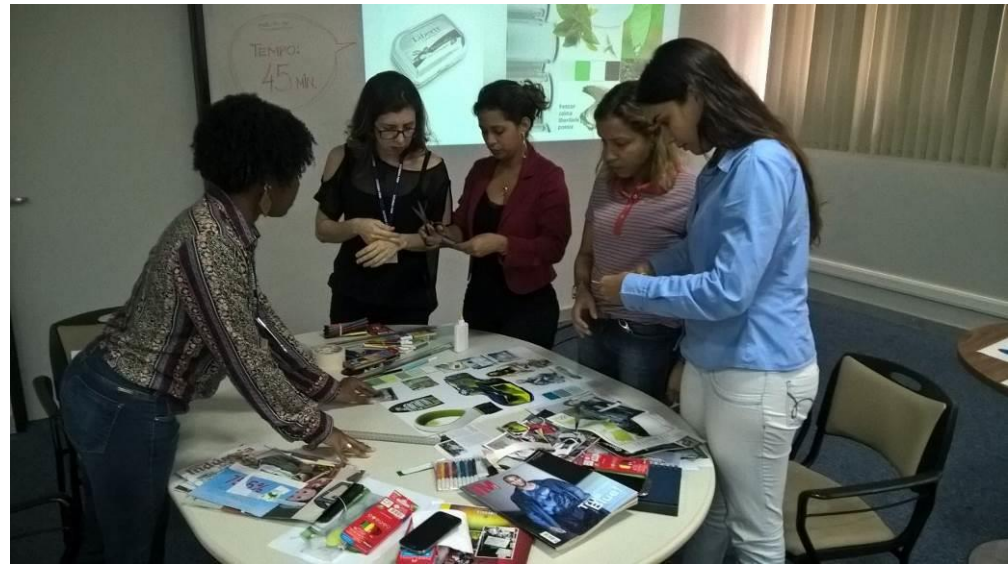

Fonte: Elaborado pelos autores com base na pesquisa realizada.

O moodboard de referência é um meio e suporte para gerar, analisar e sintetizar a informação, facilitar o diálogo e revelar dados, relações e campos de exploração para posterior construção de soluções. Conforme visto nas figuras 14 e 15, os moodboards foram elaborados com recortes de imagens de revistas que tivessem aderência à nova proposta de produto a ser concebido, fazendo uma ressignificação de modo que fosse criado a partir dos elementos destacados, como público alvo, formas, cores, ambientes, materiais, entre outros. 
Figura 14 e 15 - Moodboard - elementos de referência ressignificação do produto

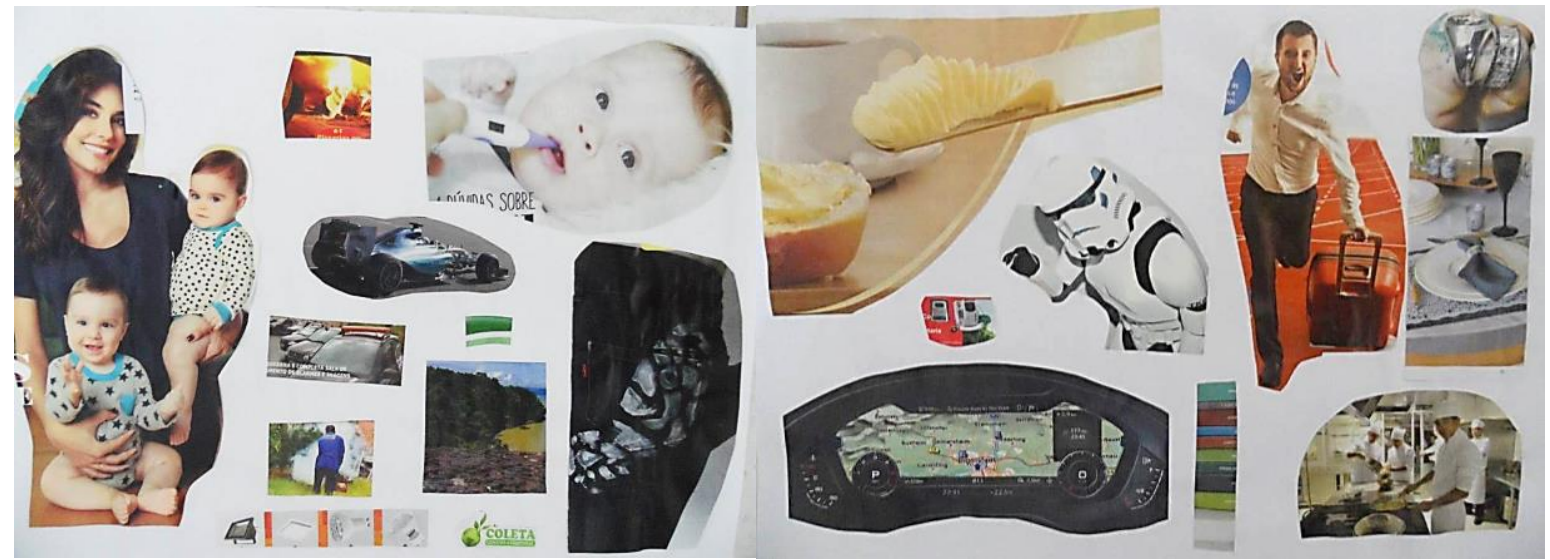

Fonte: Elaborado pelos autores com base na pesquisa realizada.

Após elaboração dos dois painéis, cada equipe apresentou seus trabalhos com os resultados obtidos para os demais participantes (figura 16), apontando o detalhamento das partes dos produtos consideradas significativas para o moodboard. No segundo painel justificaram cada elemento da referência e sua relação com o painel anterior, mostrando a ligação entre as ferramentas.

Os mediadores explicaram que, em um processo de desenvolvimento de novas ideias, na qual não existe um produto referência, a ordem das atividades é invertida. Sendo assim, o moodboad apresenta as referências da ideia do produto/serviço, na qual deseja-se transformar em real o que ainda está no imaginário.

Figura 16 - Apresentação dos Moodboards - desconstrução e referência

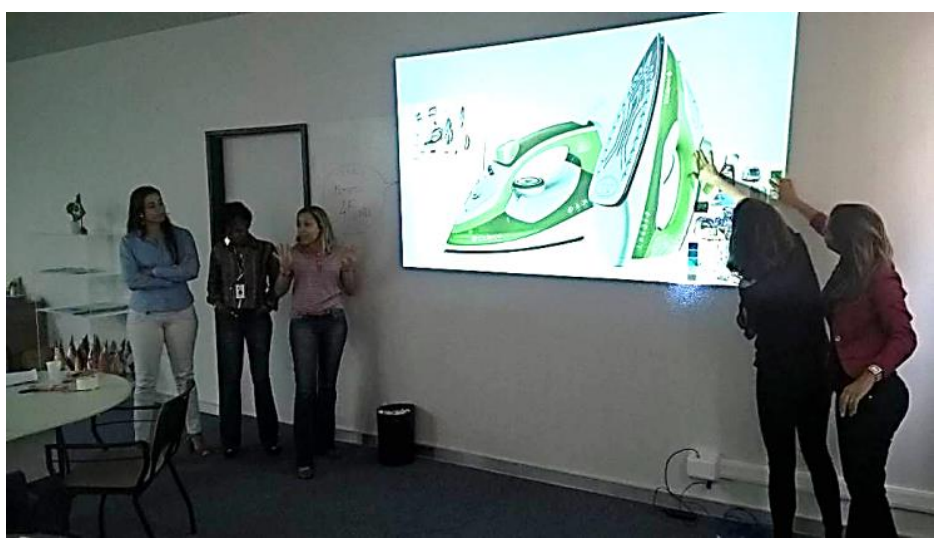

Fonte: Elaborado pelos autores com base na pesquisa realizada.

Tomando por base o último moodboard, de ressignificação do produto, foi aplicada a ferramenta de geração de ideias colaborativas, o método 635 ou Brainwriting 635, onde os componentes das equipes contribuíram na geração de ideias de um novo produto definido pelo grupo, utilizando-se dessas referências obtidas, gerando conceitos, conforme um dos resultados visto na figura 17. 
Figura 17 - Método 635 ou Brainwriting 635 - geração de ideias

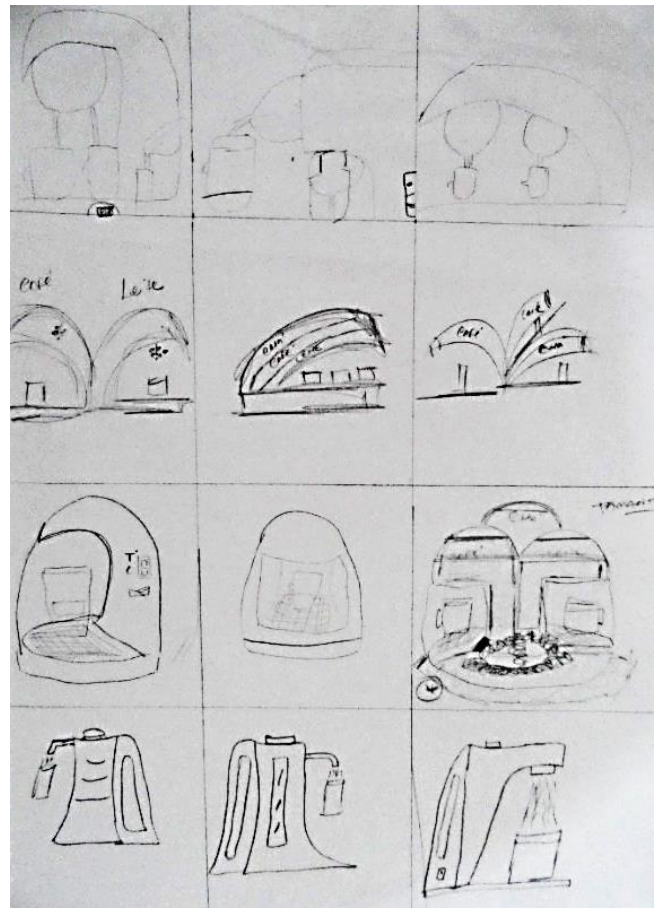

Fonte: Elaborado pelos autores com base na pesquisa realizada.

Dando continuidade à prática, foi selecionada uma das propostas concebidas na figura 17, atribuindo melhorias com contribuições dos participantes da equipe, realizando análise a partir de uma matriz de decisão. A solução foi redesenhada para apresentação aos demais participantes da sessão colaborativa, conforme visto na solução encontrada por um dos grupos na figura 18.

Figura 18 - Conceito proposto após MESCRAI

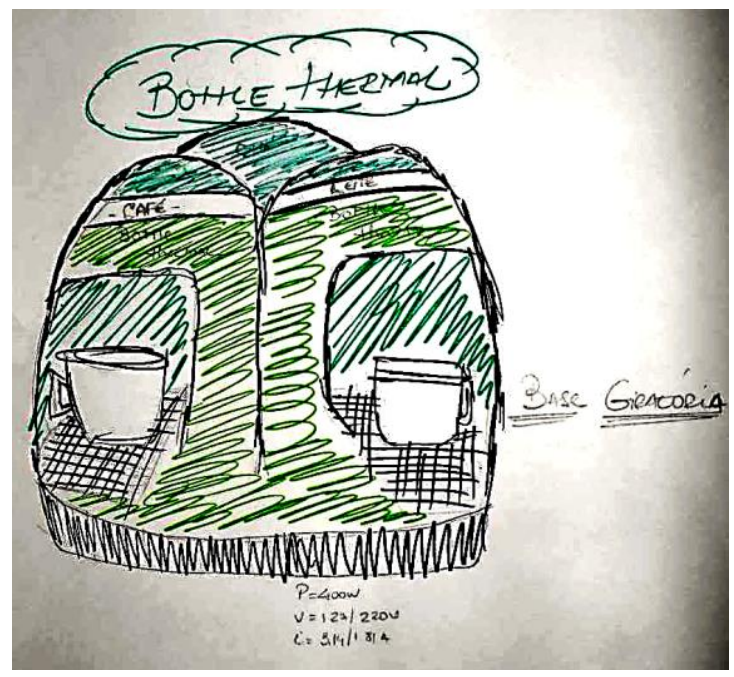

Fonte: Elaborado pelos autores com base na pesquisa realizada. 


\section{Considerações finais}

A análise das sessões colaborativas e as soluções apresentadas estabeleceram o envolvimento dos participantes nas ações descritas, com especial destaque para os resultados apresentados e depoimentos dos coordenadores de curso, os quais expuseram suas percepções e considerações sobre os ganhos com a experiência proposta.

Os participantes exibiram satisfação com os conhecimentos adquiridos e avaliaram as sessões como bastante produtivas e eficazes, pois proporcionaram experiências e estímulo à criação de conceitos, despertando a percepção visual para detalhes não observados no dia a dia em suas atividades acadêmicas. Os conhecimentos explorados oportunizaram vivências que, conforme relatos, serão replicadas nas turmas e também compartilhadas com o gestor da instituição de ensino, o qual garantiu apoiar mais ações com o objetivo de estimular a criatividade, favorecendo o desenvolvimento dos projetos de final de curso elaborados pelos alunos em fase final de formação.

Também foi observado na análise que, em alguns momentos, nos quais a mediação tornouse difícil, foi percebido certos participantes mais dispersos quanto às orientações das práticas propostas, comprometendo alguns resultados, embora a continuidade das atividades tivesse sido necessária para promover a análise e a síntese das atividades realizadas pelos grupos. Entretanto todos mostraram-se motivados pelas experiências na sessão colaborativa.

Propõe-se, com base nas discussões apresentadas, a realização de novas sessões colaborativas envolvendo os alunos do último período de formação, de modo a estimular a geração de ideias no ambiente institucional mediadas pelo design e aplicando o método colaborativo, visando promover a concepção de maior número de alternativas na etapa conceitual dos projetos de final de curso. Diante dos resultados, é possível afirmar que a criatividade pode ser estimulada e não ensinada, pois é possível aprender a pensar e fazer surgir o potencial criativo existente nas pessoas.

\section{Referências}

BAXTER, Mike. Projeto de Produto: guia prático para o desenvolvimento de novos produtos. São Paulo: Edgard Blücher, 2001.

BROWN, Tim. Design Thinking: uma metodologia poderosa para decretar o fim das velhas ideias; tradução: Cristina Yamagami. Rio de Janeiro: Elsevier, 2010.

DE MASI, Domênico. Criatividade e Grupos Criativos. Rio de Janeiro: Sextante, 2003.

DESERTI, A. Possible trajectories for design consulting. Politécnico de Milano, 2012, 5 slides: color

CARAVEGNA, Erik. Branding e Storytelling. Politécnico de Milano, 2011, 34 slides: color

GUERRERO, V. Análise do gerenciamento de informação em um ambiente colaborativo e distribuído de desenvolvimento de produto. 2001. São Carlos, Dissertação (Mestrado) Departamento de Engenharia Mecânica, Escola de Engenharia de São Carlos, Universidade de São Paulo, 2001.

MANZINI, Ezio. Design para a inovação social e sustentabilidade: comunidades criativas, organizações colaborativas e novas redes projetuais. Rio de Janeiro: E-papers, 2008. 
MCDONAGH, D.; DENTON, H., Exploring the degree to which individual students share a common perception of specific mood boards: observations relating to teaching, learning and team-based design. Design Studies, 2005, 26, (1), 35-53.

PAZMINO, Ana Verônica. Como se Cria: 40 Métodos para Design de Produtos. São Paulo: Edgard Blücher, 2015.

SILVA FILHO, Antônio Mendes. Inovação requer um processo criativo dinâmico e entusiasmo. Revista Espaço Acadêmico, № 124, Ano XI, setembro 2013, p. 44-48. Disponível na internet: http://www.periodicos.uem.br/ojs/index.php/EspacoAcademico/article/viewFile/21826/11574

SILVA FILHO, Antônio Mendes. Criatividade em ação na tomada de decisão. Revista Espaço Acadêmico, № 127, Ano XIII, dezembro 2011, p. 08 a 11. Disponível na internet: http://periodicos.uem.br/ojs/index.php/EspacoAcademico/article/view/15424/8334

SAMPAIO, João Nunes. Narrativa e visualização: estratégias para a eficácia na prática do design colaborativo. Tese (Doutorado) - Departamento de Comunicação e Arte, Universidade de Aveiro, 2016.

TERRA, José Claudio et al. 10 dimensões da Gestão da Inovação: uma abordagem para transformação Organizacional. Rio de Janeiro, Elsevier, 2012.

VIANNA, Maurício. Design Thinking: inovação em negócios. 2. ed. Rio de Janeiro: MJV, 2013. 